\title{
High-Dose Poisoning, “Body Packers” Case That Ended in An Emergency: A Case Report
}

\author{
Adem Çakir*, Ramazan Guven and Kemal Şener \\ Department of Emergency Medicine, Republic of Turkey Ministry of Health Basaksehir Cam and Sakura City Hospital, Turkey
}

Submission: December 01, 2021; Published: December 16, 2021

*Corresponding author: Adem Çakır, Attending Physician, Department of Emergency Medicine, Republic of Turkey Ministry of Health Basaksehir Pine and Sakura City Hospital, Turkey

\section{Abstract}

Background: Body packing cases are a global public health problem with an increasing prevalence today. This situation, which involves a difficult process in both legal and medical terms, is particularly challenging for emergency room clinicians. Effects of body packing on the emergency department, Due to the low profit margin of methamphetamine, we see it rarely compared to cocaine and heroin. With mechanical obstruction and rupture of packages are common problems. The rupture of the packs, they may come to the emergency room clinician with toxidromas.

Case: A 19-year-old male patient was brought to the emergency department after cardiopulmonary resuscitation. Imaging tests of the patient who had symptoms of sympathomimetic toxidroma upon arrival revealed multiple substance packs. Without a systemic evaluation algorithm in diagnosis and treatment of body packing state, clinicians have difficulties in this issue and delays may be experienced in both diagnosis and treatment in this rare issue. However, complex management of these patients in the emergency department prevents these delays. Bedside x-ray, USG, endoscopy and hemofiltration of the patient were performed in the emergency department. Follow-up and treatment of the patient continued in the emergency critical care unit after all procedures.

Conclusion: In our case, we presented the management of the diagnosis and treatment process in the emergency department of a patient who had symptoms of sympathomimetic toxidroma, brought to the emergency room after cardiopulmonary resuscitation and found to have methamphetamine toxicity at the end of the evaluations.

Keywords: Body Packing; Methamphetamine; Emergency; Critical Care

\section{Introduction}

"Body Packing" refers to the condition of being concealed in the anus or vagina (insertion into the body), filling the body (swallowing) for international illegal drug trafficking [1-3]. The first case of body packing was reported in the literature in 1973, with a case who swallowed a cannabis-filled condom and was hospitalized due to intestinal obstruction [4]. It is frequently observed that people with low socioeconomic level, youngmiddle age group and frequently low addiction level are users or non-users [5]. In addition, there was an increase in the types of substances carried and improvements in the form of substance packaging in body carrier. Body transport has become a major phenomenon with airline transport, as the customs still do not have the technology to detect this situation and a large amount of drug trafficking can be done at a time. The most common death in "body packing" cases is the result of acute toxicity occurring at high doses due to rupture of the packs. In addition, acute toxicity can be seen because the packages are semi-permeable. Deaths are rarely reported in the literature due to mechanical complications other than poisoning [4-6]. Therefore, it is necessary to diagnose these patients and start treatment as soon as possible. Radiological imaging has an important role in detecting body packages in drug carriers [7].

Although cocaine is the most commonly trafficked drug worldwide, the number of methamphetamine carriers is increasing day by day $[4,8,9]$. Methamphetamine (MAH) is an extremely potent and highly addictive chemical agent that causes serious psychiatric, cognitive, medical, socioeconomic and legal consequences [10]. It was first produced by Akira Ogata in 1919 and was produced on a large scale as MAH hydrochloride known as "crystal meth" [11]. Since MAH has high lipophilicity, it passes the blood-brain barrier easily and can be distributed well to tissues with high lipid content. In addition, it is extensively metabolized in liver isoenzymes including CYP2D6. Although MAH is mostly excreted in urine, it is also eliminated by sweat and saliva. Its 
half-life is on average 9-12 hours [12,13]. In our study, the clinical course of a patient who developed multi-organ failure due to rupture of one of the MAH packages carried in the gastrointestinal system and the resuscitation algorithm in the emergency service in a case with body packing was described $[14,15]$.

\section{Case}

A 19-year-old male case was brought to our emergency department by the 112 emergency health services. In the history of the patient, it was learned that after getting off the plane, he applied to the health facility after getting worse, and there was cardiopulmonary resuscitation for 5 minutes after sudden cardiopulmonary arrest. Endotracheal intubation was performed on admission, and it was observed that vital values were unstable. On examination, it was observed that the patient was tachycardic (HR: 142 beats / min), hypertensive (175/92 $\mathrm{mmHg})$, hyperthermic $\left(39,8^{\circ} \mathrm{C}\right)$ and tachypneic (26 / min). 3 of the Glasgow coma scale (GCS) was noted as unconscious, noncooperative, non-oriented. The patient's skin was moist. There was real in the respiratory examination of the patient, but no rhonchus was heard. Bowel sounds were not heard during the abdominal examination. Rectal touch was unremarkable. There was no neck stiffness, pupil evaluation was fixed-mydriatic and the light reflex was not obtained. Dark urine output was observed in the Foley catheter application. This condition was evaluated as macroscopic myoglobinuria and was associated with rhabdomyolysis clinic.

In the examinations of the patient; WBC: 20900 / mm3, neutrophil 19560 / mm3, PLT: 209.000 and hemoglobin 17,0 mg / dL were found in whole blood analysis. There was an increase in the kidney function tests of the patient (creatinine: $4,55 \mathrm{mg} / \mathrm{dL}$ and BUN: 35.4), creatinine kinase (CK) was $47.450 \mathrm{U} / \mathrm{L}$, troponin value was: $492 \mathrm{mg} / \mathrm{dL}$, liver function tests increased (ALT: 2570). U / L, AST: 3027 U / L), INR value was found to be 2.5. In the blood gas analysis, it was seen that $\mathrm{pH}: 7.29$, Lactate: $3.1 \mathrm{mmol} / \mathrm{L}$ and HC03: $12.8 \mathrm{mmol} / \mathrm{L}$. In the bedside portable x-ray imaging of the patient, oval or round gas densities were observed due to multiple gas trapped around the package (Figure 1A). In the bedside ultrasonography, multiple items that were thought to be foreign bodies that formed multiple images of shadowing in the posterior and in the foreground were detected (Figure 1B). Later, in the upper and lower abdominal tomography, it was seen that there were multiple foreign bodies with dimensions of approximately 28x12x12 mm (Figure 1C \& 1D). Considering the current condition of the patient, the foreign bodies in the abdomen were thought to be packages with sympathomimetic chemical agent content. When physical examination, laboratory results and imaging tests were examined, it was thought that this situation might be caused by a sympathomimetic substance toxidroma.

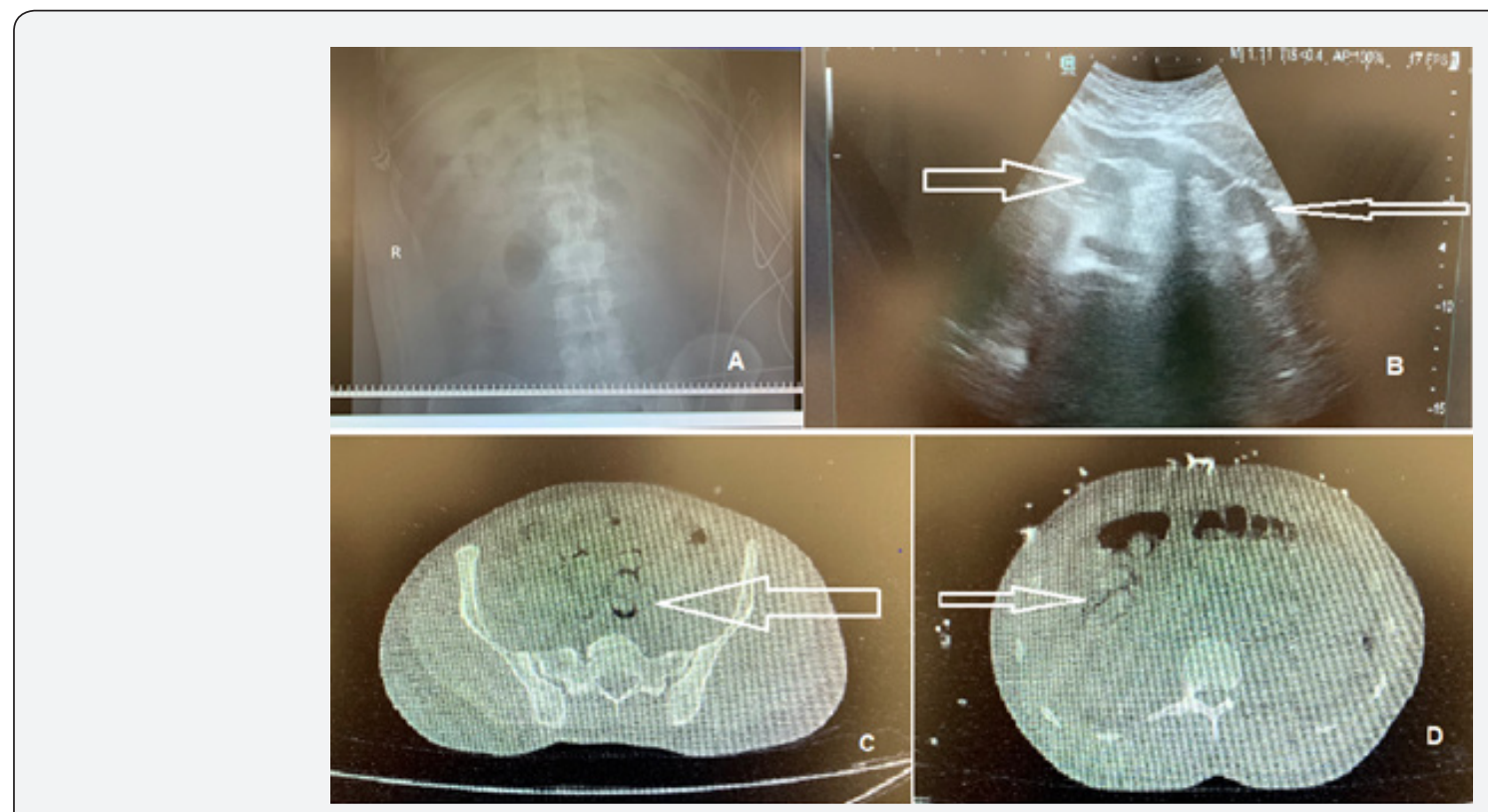

Figure 1: Foreign body (pack) images on CT imaging of the patient

(White arrow: Foreign body images)

The hydration of the patient was made upon his arrival. For hyperthermia, $10 \mathrm{mg} / \mathrm{mL}$ paracetamol (2x1000 mg in 6 hours in total) and cold application were used. Beta blocker (Esmolol) was applied to the patient with normal sinus rhythm and sinus tachycardia and hypertension to ensure perfusion. Upon the suspicion of Covid-19, oral and nasal swab samples were taken from the patient for PCR and sent to the laboratory. Activated charcoal and laxatives were given to the patient because of the high suspicion of rupture. Hemodialysis was planned for the patient with myoglobinuria and high creatinine and INR in laboratory examinations, when the urine output was $100 \mathrm{cc}$ in 4 hours, and 4-prothrombin complex concentrate $(1250 \mathrm{U} / 50 \mathrm{ml}$ 


\section{Open Access Journal of Toxicology}

4-PCC $100 \mathrm{~min}$. also in the form of infusion). In the endoscopic examination performed on the patient, multiple foreign bodies of similar sizes started to be seen from the antrum of the stomach (Figure 2). Packages seen in the stomach were removed (Figure 3). Ulcerated areas created by MAH on the stomach wall were observed in the endoscopic examination (Figure 4). Despite the treatment, the ultrafiltration procedure was continued after the laboratory tests showed that there was no improvement and the multi-organ failure continued. Upon improvement in blood gases (pH: 7.33, HCO3: 21.9, PO2: 98, PCO2: 28, lactate: 0.9) after 5 days of follow-up in the critical area in the emergency department, the patient was transferred to the ICU. As a result of toxicological tests in the blood and urine samples taken, the case was confirmed to have methamphetamine toxidroma.

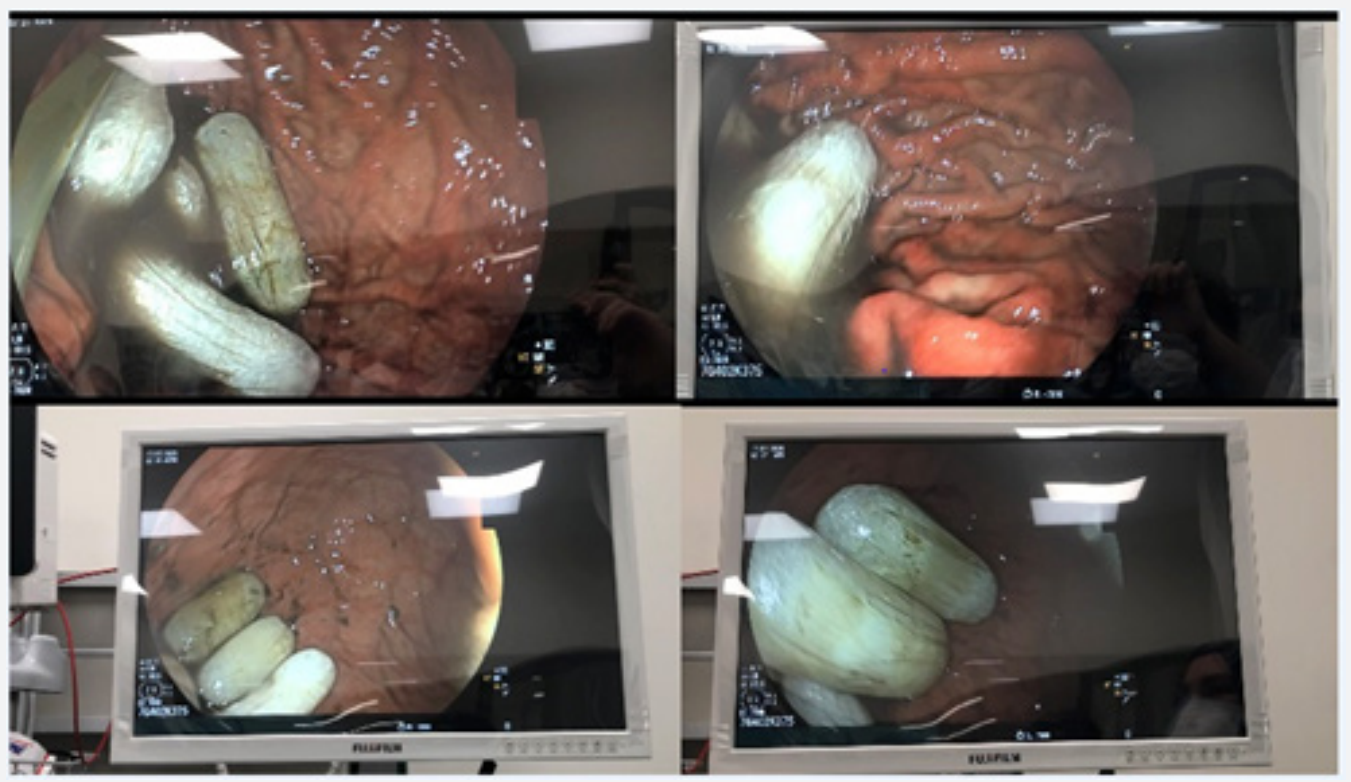

Figure 2: Foreign bodies seen in stomach and duodenum during endoscopic examination performed in the Emergency Department.

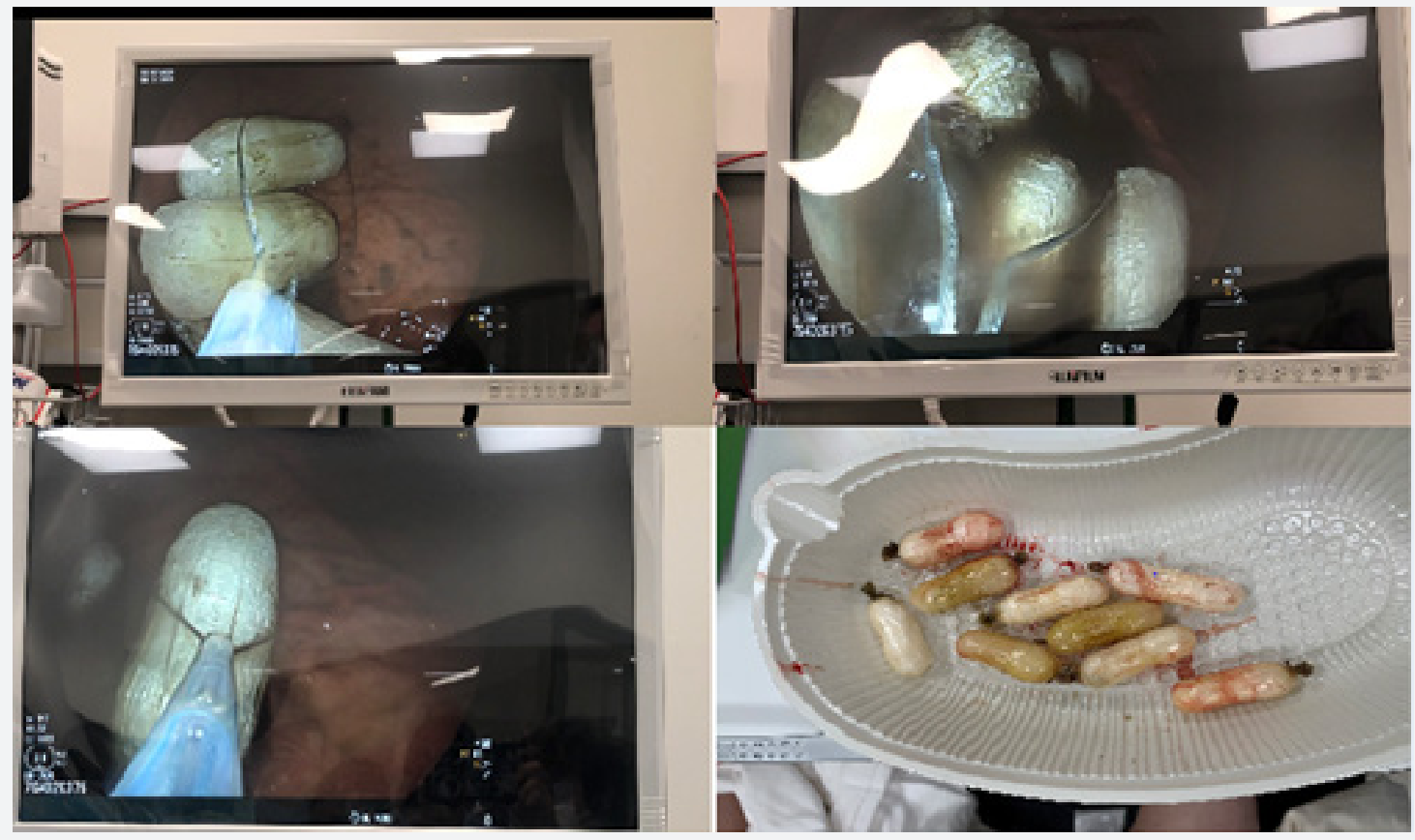

Figure 3: Images of foreign body removal by endoscopic intervention. 


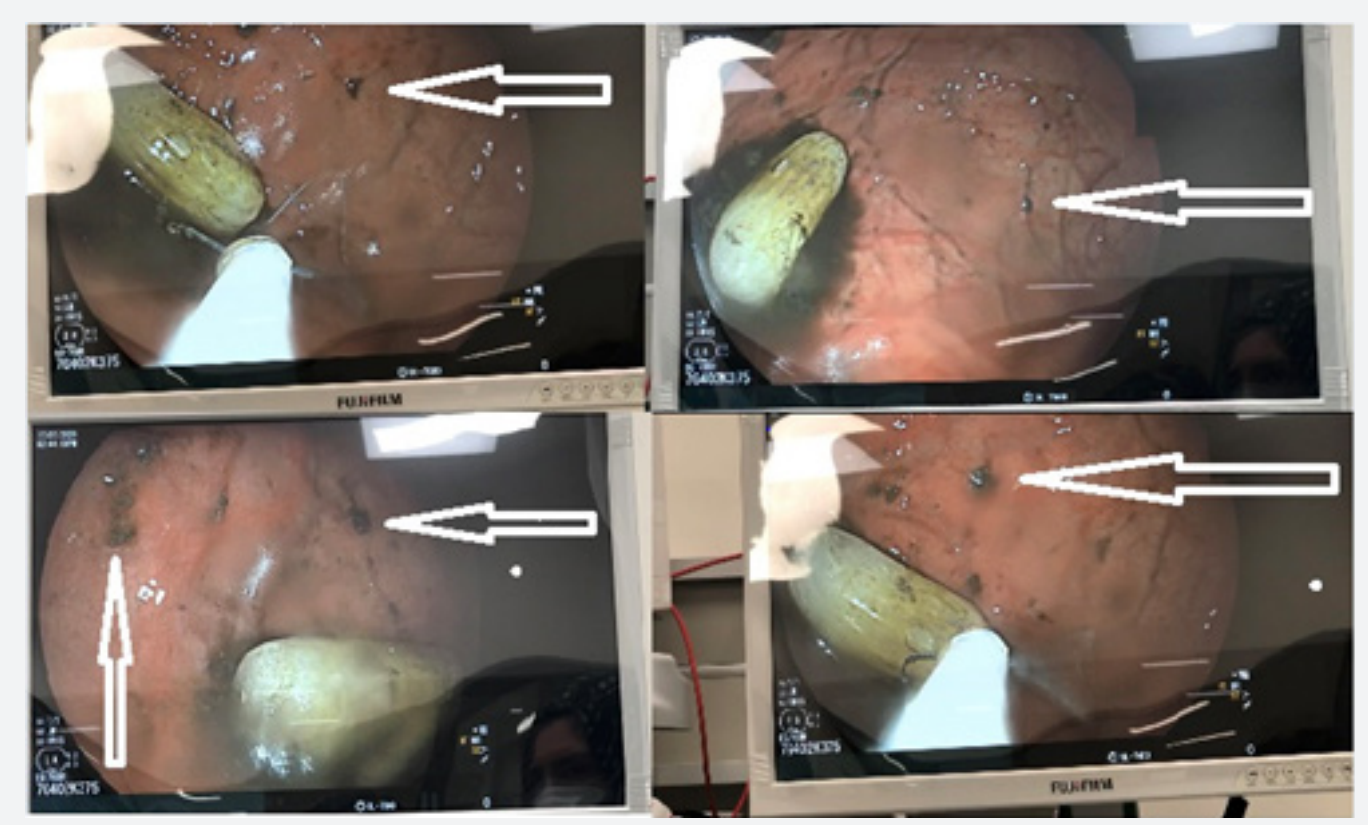

Figure 4: Ulcerated areas caused by packages or ruptures in endoscopic intervention.

(White arrow: Ulcerated areas in the intestinal mucosa seen during endoscopic intervention).

\section{Discussion}

Cocaine is the most common drug detected in body carriage (70-90\%). Heroin body packing is the second most common follow-up after cocaine [5]. However, while other narcotics such as MAH are rarely carriers due to lower profit margins compared to cocaine and heroin; Due to its easy synthesis, affordable price for the user and having a continuous effect, its number has increased today. Although cocaine and opiate body carrier accidents (such as rupture and leakage) are frequently reported, MAH body carrier is rarely reported in the literature [16,17]. An intense loading ritual is applied for body carriage. In the country where body carriers will be loaded, a good bowel preparation and cleaning is usually done before loading. Afterwards, the carrier swallows the substances under sedation and uses medication for reduces the bowel movements during the carriage. At the destination, the drug is given to speed up the passage and the substance packages are evacuated. In case of rupture or leakage of one of the packages, toxicity may occur due to high dose substance intake, and it carries a high mortality risk. Most of the reported cases are detected by autopsies $[18,19]$. When body packing cases apply to the emergency room, it is difficult for the emergency department physician due to the lack of a diagnostic algorithm and the absence of a systemic approach in treatment. Our case was a case of MAH body packing and was brought to the emergency department after cardiopulmonary arrest and no history was obtained. The case was diagnosed especially because of giving toxidroma clinic and early treatment was started, however, this process will be very difficult for the clinician in a patient who has not settled in toxidroma clinic early. In body packing publications in the literature, it has been reported that the clinician may overlook the packages on x-ray imaging in these cases [20]. Although many foreign bodies were observed in bedside x-ray imaging in our case, it was understood from the patient's clinic that this image was a multiple item package. In such cases, besides the X-ray imaging does not provide clear information, diagnostic evaluation with non-contrast abdominopelvic CT is recommended in body packing cases in the literature. It is also reported to be the best diagnostic method for determining the presence and number of packs in these patients [21].

In body packing cases, the clinic is in a broad spectrum and treatment planning is made according to these clinics. In some cases, ileus develops in body packing due to mechanical obstructions and surgical treatment may be required in these cases. In addition, due to the rupture of the packages, toxidrom clinic is developing and appropriate treatment planning is made for these toxidromes. In our case, upon the observation of the packages after imaging and the intense clinical observation of toxidroma, rupture was considered, and appropriate packages were removed from the packages by endoscopic intervention in order to determine the substance and to reduce the retoxicity by preventing the recurrence of package ruptures. Activated charcoal was given to the patient who was found to have body packing and was thought to have possible package rupture. In addition, laxatives were added to the treatment. In the literature, for all body fillers or body packers, osmotic laxatives (lactulose) or polyethylene-glycol (PEG) are recommended in body fillers with activated charcoal [22]. In our case of MAH body packing, we followed up in our emergency critical care area for 5 days after 
the procedure was completed and the treatment was planned. Since it is ensured that all packages are removed in body packing cases in the literature, follow-up for 2 more days without clinical symptoms is recommended. In addition, it has been reported in the literature that $14 \%$ of the cases need a second CT scan to ensure that all packages are removed [23]. In our case, we did not plan a second CT imaging in the critical area follow-up.

\section{Conclusion}

We have seen that there is no diagnosis and treatment algorithm in the literature about body packing and this is needed. In addition, we think that the duration of treatment in these cases is long. The clinician should be careful due to the risk of rupture and keep in mind that rapid clinical deterioration may occur.

We presented the emergency department management of a patient with MAH toxidroma who was brought to our hospital after cardiopulmonary arrest and was diagnosed with body packing, from the moment of diagnosis to clinical stabilization.

\section{References}

1. Sengupta A, Page P (2008) Window manipulation in diagnosis of body packing using computed tomography. Emerg Radiol 15(3): 203-205.

2. Krishnan A, Brown R (1999) Plain abdominal radiography in the diagnosis of the "body packer." J Accid Emerg Med 16(5): 381.

3. Horrocks AW (1992) Abdominal radiography in suspected "bodypackers." Clin Radiol 45(5): 322-325.

4. Peake ST, Das S, Greene S, Dubrey SW (2009) Cocaine 'body packers' and the clinical management of packet rupture. Br J Hosp Med 70: 110111.

5. Cappelletti S, Aromatario M, Bottoni E, Fiore PA, Straccamore M, et al. (2016) Drug-related deaths with evidences of body packing: two case reports and medico-legal issues. Leg Med 20: 23-26.

6. Introna Jr F, Smialek JE (1989) The "mini-packer" syndrome. Fatal ingestion of drug containers in Baltimore, Maryland. Am J Forensic Med Pathol 10 (1): 21-24.

7. Beck NE, Hale JE (1993) Cocaine "body packers." Br J Surg 80(12): 1513-1516.

8. Flach PM, Ross SG, Ampanozi G (2012) "Drug mules" as a radiological challenge: sensitivity and specificity in identifying cocaine in body packers, body pushers and body stuffers by computed tomography, plain radiography and Lodox. Eur J Radiol 81(10): 2518-2526.
9. Gill JR, Graham SM (2002) Ten years of "body packers" in New York City: 50 deaths. J Forensic Sci 47(4): 843-846.

10. Hutchins KD, Pierre-Louis PJ, Zaretski L, Williams AW, Lin RL, et al. (2000) Heroin body packing: three fatal cases of intestinal perforation. J Forensic Sci 45(1): 42-47.

11. Taheri MS, Hassanian-Moghaddam H (2008) Swallowed opium packets: CT diagnosis. Abdom Imagine 33(3): 262-266.

12. L Karila, A Weinstein, HJ Aubin, A Benyamina, M Reynaud, et al. (2010) Pharmacological approaches to methamphetamine dependence: a focused review. Br J Clin Pharmacol 69(6): 578-592.

13. Panenka WJ, Procyshyn RM, Lecomte T, MacEwan GW, Flynn SW, et al. (2013) Methamphetamine use: a comprehensive review of molecular, preclinical and clinical findings. Drug Alcohol Depend 129(3): 167179.

14. Cruickshank CC, Dyer KR (2009) A review of the clinical pharmacology of methamphetamine, Addiction 104(7): 1085-1099.

15. Schep LJ, Slaughter RJ, Beasley DM (2010) The clinical toxicology of metamfetamine. Clin Toxicol (Phila) 48(7): 675-694.

16. Logan BK, Weiss EL, Harruff RC (1996) Case report: distribution of methamphetamine in a massive fatal ingestion. J Forensic Sci 41(2): 322-333.

17. Kashani J, Ruha AM (2004) Methamphetamine toxicity secondary to intravaginal body stuffing. J Toxicol Clin Toxicol 42(7): 987-989.

18. De Bakker JK, Nanayakkara PW, Geeraedts LM Jr, de Lange ES, Mackintosh MO, et al. (2012) Body packers: a plea for conservative treatment. Langenbecks Arch Surg 397(1): 125-130.

19. Takekawa K, Ohmori T, Kido A, Oya M (2007) Methamphetamine body packer: acute poisoning death due to massive leaking of methamphetamine. J Forensic Sci 52(5):1219-1222.

20. Berger FH, Nieboer KH, Goh GS, Pinto A, Scaglione M (2015) Body packing: a review of general background, clinical and imaging aspects. Radiol Med 120(1): 118-132.

21. Ab Hamid S, Abd Rashid SN, Mohd Saini S (2012) Characteristic imaging features of body packers: a pictorial essay. Jpn J Radiol 30(5): 386-392.

22. Traub SJ, Su M, Hoffman RS, Nelson LS (2003) Use of pharmaceutical promotility agents in the treatment of body packers. Am J Emerg Med 21(6):511-512.

23. Heymann Maier L, Trueb L, Schmidt S, Carron PN, Hugli O, et al. (2017) Emergency department management of body packers and body stuffers. Swiss Med Wkly 147: w14499.

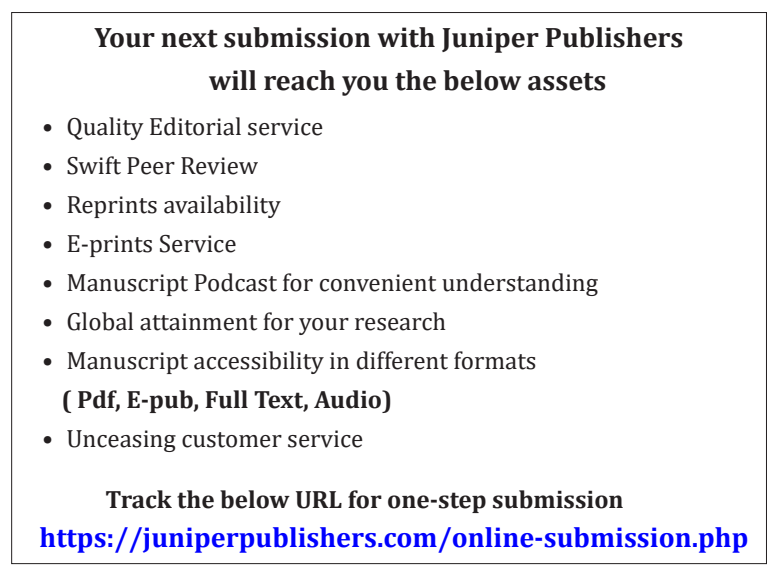

